\title{
ALTICID BEETLES WITH 128 SPERM CELLS PER BUNDLE
}

A recent paper ${ }^{2}$ indicates that primitive and unspecialized insects tend to have a higher number of spermatozoa per bundle (spz/b) than modern and specialized ones. There is some reason to believe that the reduced $\mathrm{spz} / \mathrm{b}$ reflects a reduced total production of spermatozoa. This also might have adaptive value in reducing genetic variability. Thus, spz/b might serve as a rough indicator of the degree of specialization the insect has reached during its phylogenesis. This certainly does not hold true in all cases because there may be other, even opposite, trends of adaptive value concerning the sperm production. Specialization in parasitism thus tends to require an increasing number of gametes to assure fertilization. Advanced care for the progeny, on the contrary, facilitates reduction of the number of gametes.

Among the bisexual alticids, the chances for fertilization are supposedly good, and similar throughout the family. The most primitive species, Forsterita sp., has $256 \mathrm{spz} / \mathrm{b}$, while the most advanced species (subtribe Oedionychina, of the tribe Oedionychini), have the smallest known number; only $16 \mathrm{spz} / \mathrm{b}$. Species with $32 \mathrm{spz} / \mathrm{b}$ are very common while those with $64 \mathrm{spz} / \mathrm{b}$ are much less common, except for species in the primitive tribe Alticini. Species with $128 \mathrm{spz} / \mathrm{b}$ apparently are encountered infrequently. Only a few unidentified instances, one of them an Ocnoscelis, were known when the above cited paper was published, and none of the bundles were depicted. Since publication of that paper, I have encountered an additional species with $128 \mathrm{spz} / \mathrm{b}$ which has been determined as Cacoscelis compta Erichson. The anterior part of its sperm bundle is illustrated in figure 1. The only specimen found was collected at Hacienda Pampa Whaley in the valley of Chanchamayo, Central Perú, on November 23, 1965.

Niilo Virkki

Department of Genelics

I I am indebted to Mrs. Doris Blake, U.S. National Museum, Smithsonian Institution, Washington, D.C., for taxonomic determination of the Cacoscelis specimen. The collection was possible due to the grant GB-1917, of the National Science Foundation.

2 Virkki, N., Sperm bundles and phylogenesis, Zeitschr. Zellf. mikr. Anat. 101: $13-27,1969$. 


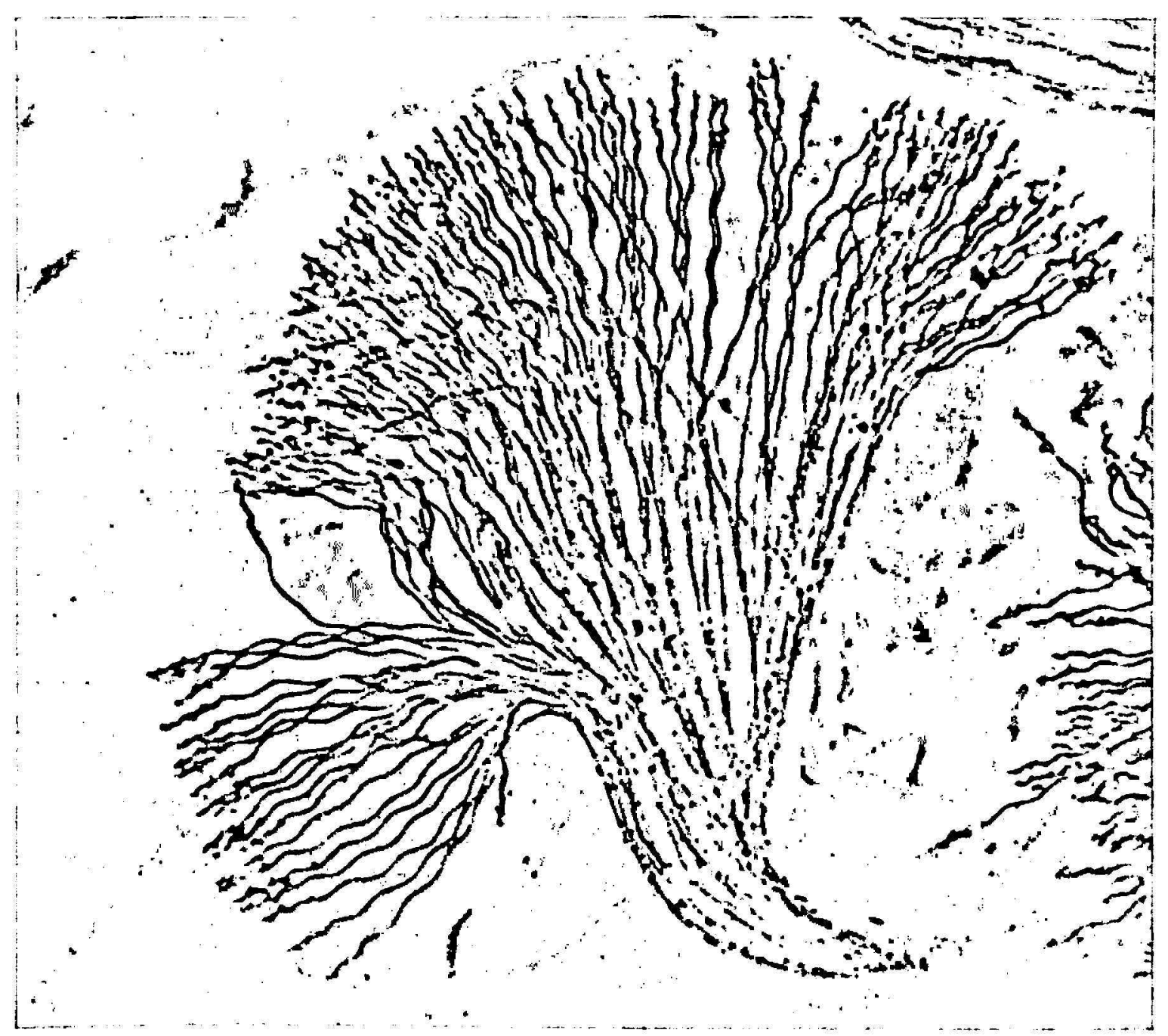

FIG. 1.-Cacoscelis compla Erichson: Anterior part of the sperm bundle, $\mathrm{spz} / \mathrm{b}=$ 128. Phase contrast, $800 \times$. 